\title{
Photochemical Treatment as an Alternative to Improve the Quality of Wastewater After Advanced Primary Treatment
}

\author{
HERNÁNDEZ FERNANDO'*, RIVERA ANTONIO², ROMERO OMAR², \\ TORRES EDUARDO ${ }^{1}$, ORTEGA MARIANA ${ }^{3}$, DÍAZ MERLE YURIDIA ${ }^{4}$ and GARCIA SANDRA ${ }^{1}$
}

${ }^{1+}$ Centro de Química, ICUAP, BUAP, ${ }^{2}$ Centro de Investigaciones en Ciencias Microbiológicas, ICUAP, BUAP, ${ }^{3}$ Facultad de Ingeniería Química, Colegio de Ingeniería Ambiental BUAP y ${ }^{4}$ Instituto Tecnológico Superior de la Montaña, México.

http://dx.doi.org/10.13005/ojc/300412

(Received: July 26, 2014; Accepted: September 03, 2014)

\begin{abstract}
The present research contains the photochemical treatment (PCT) of residual wastewater effluent derived from an advanced primary treatment process (APT). The application employed an ultraviolet light system, hydrogen peroxide and ozone as a free hydroxyl's radicals generator; strong oxidants for the organic contaminants mineralization which affects the water quality. The aliquots of the APT and PCT were analyzed by determination of the parameters as the color, turbidity, electric conductivity, COD, UV-Vis spectrometry, anion and cation techniques, enabling the determination of the photo-oxidative wastewater treatment efficiency. The microbiological assays denote the one hundred percent photo-oxidative effectiveness for the removal of undesirable microorganisms. After the treatment, the water is suitable for its reuse, commercialization or spill into a body receptor without any risk for the environment or the health.
\end{abstract}

Keywords: Photo-oxidation, microorganisms, disinfection, wastewater

\section{INTRODUCTION}

The water is a unique substance that exists both in large quantities and in the three states of natural aggregation. Is one of the most important compounds for the live organism on the Earth, constituting a medium for their nutritional and secretion functions. Due to it multiple uses inside the satisfaction of human requirements, it is inescapable to value the grade of contamination and the treatments which permits its possible reuse or reintegration into the biosphere without undesirable ambient effects.

The natural water cycle supplies a great capacity of purification, that facility for regeneration and its apparent infinity plenitude induce the misleading concept about the water resource, considering it as a residual dump for a great amount of chemical and radioactive compounds, pesticides, heavy 
metal, etc., make it dangerous for the human health and the environment, owing the amount of contaminants presents into the residual water ${ }^{1}$.

The advanced primary treatment (APT) is a method for the conditioning residual water which is based onto the removal of the majority of the colloidal constituents and biologic pathogens by the use of coagulation-flocculation, sedimentation, filtration and disinfection techniques. Its principal objective is the elimination of the solids in suspension adding flocculants and coagulants ${ }^{2}$.

The advanced oxidation processes (AOP's) have a great potential for its application over a lot of treatment areas of residual water that contains oxidizable contaminants, is supported onto the high oxidizing power of the hydroxyl radicals, a transitory specie for the oxidation of organic compounds to simple substances, preferential carbon dioxide and water, it is also used for the oxidation of the inorganic compounds with a low oxidation state ${ }^{3}$. The AOP's have been employed for the conditioning of the water coming from groundwater and sulphide deposits ${ }^{4-5}$, textile, pharmaceutical $^{6}$, food, paper, chemical, and other industrial processes. However, their use has not been widely applied yet, because the specific conditions and calculation of doses of reagents needed for complete mineralization of organic compounds functioning must be determined through experimentation for effective wastewater treatment.

The hydroxyl radicals are possibly produced inside the different photochemical systems like: UV light $/ \mathrm{H}_{2} \mathrm{O}_{2}$ [7], UV light $/ \mathrm{O}_{3}$, UV light $/ \mathrm{H}_{2} \mathrm{O}_{2} / \mathrm{O}_{3}$ [8], photofenton [9], UV light $/ \mathrm{TiO}_{2}[10]$, etc. The microorganism present into the water, need their nuclei, cellular membrane and organic material constitution for live. When water is treated with ultraviolet light, the microorganism die or had been temporary inactivated, if the light exposition time is not sufficient, it is possible that the microorganism find again the adequate conditions for their grown and multiplication. Some microorganisms are pathogenic and cause diseases in general are bacteria, viruses, protozoa and worms from domestic sewage and decomposition of animal wastes $^{11-15}$.
The germicidal range is found between the 240 and 280 nanometers, reaching the maximum disinfectant efficiency onto $254 \mathrm{~nm}$. It is necessary to guarantee that all the water will be achieved by the electromagnetic radiation adequately. The exposition time is vital for the assurance of a good performance of the system, estimating for that proposes an interval of 10 to 20 seconds. A batch reactor equipped with a medium pressure mercury lamp guarantee those conditions.

\section{MATERIALAND METHODS}

The organic contaminant removal present into the water coming from an advanced primary treatment (APT) was carried out through the use of both a batch photo-reactor and a solar collector, systems where the samples were processing with UV light/ $\mathrm{H}_{2} \mathrm{O}_{2} / \mathrm{O}_{3}$ variables. A composite sample of residual water was employed (a combination of single wastewater samples taken at predetermined in one place in order to minimize the effects of variability in individual sample intervals) filter it by a qualitative paper with $1.5 \mathrm{im}$ of retention, used for clarification and elimination of precipitates.

In the photochemical experiments a Batchtype photo-reactor was used, with a maximum capacity of $1 \mathrm{~L}$, it is equipped with a mercury medium-pressure steam UV lamp; (model PUV-1022 Heraeus) which is $110 \mathrm{~mm}$ length, with an emission spectrum in the region from 200 to $460 \mathrm{~nm}, 1000$ Watts, 145 Volts and 7.5 amperes of current. The photo-reactor has a demineralized water recirculation system for the temperature regulation. The external part of the reactor is integrated by a Pyrex glass cylindrical vessel.

The air supply was proportionate by an Elite 801 model compressor, with a flow of 2000 $\mathrm{mL} / \mathrm{min}$, which correspond to the supply of $400 \mathrm{~mL} /$ $\min$ of $\mathrm{O}_{2}$. Ozone was dispensed through a generator Hydrozon K-40, which produces $40 \mathrm{mg}$ of ozone per hour.

Photochemical treatment in the batch photoreactor, $850 \mathrm{~mL}$ was added to the photoreactor, $0.02 \mathrm{~mL}$ of hydrogen peroxide $50 \%$ were added. Ozone is added to the system through a hose containing a diffuser at its terminal point. 
This lamp is turned on and stabilized for a period of 3 minutes, in order to reach full brightness. When culminates stabilization, start measuring the photodegradation of pollutants in wastewater are collected in aliquots every 5 minutes

In the case of photochemical treatment by the use of solar collector system, the reflector surface (involute) was constructed with an aluminum foil and, as a reactor, a Pyrex borosilicate glass tube, with $95 \%$ of UV light transmission, was incorporated. The higher part of the solar collector was oriented to the North hemisphere and its lowest edge, to the terrestrial South.

For the photodegradation proceeding, 1.4 $L$ of residual water is put inside the solar collector, using a UV solar light $/ \mathrm{H}_{2} \mathrm{O}_{2} / \mathrm{O}_{3}$ system. $0.03 \mathrm{~mL}$ of $\mathrm{H}_{2} \mathrm{O}_{2}$ at $50 \%$ is added and then the recirculation system was connected to control the temperature and prevent evaporation of sample treated. $40 \mathrm{mg} / \mathrm{h}$ of $\mathrm{O}_{3}$ was added via a gas diffuser, collecting aliquots from the photodegradation process at intervals of 60 min during 5 hours. Thereafter, the amount of hydrogen peroxide residual was determined using a test with indicator strips.

$\mathrm{pH}$ determination was conducted by means of a potentiometer Conductronic, model PC16. Turbidity and color was determined using a Merck photometer, model SQ-118, methods 113 and 139 , respectively.

The COD is determined by quantification of the cuvette test (Merck). Before applying the measurement, it is necessary to measure the residual $\mathrm{H}_{2} \mathrm{O}_{2}$ present in aliquots and removed with a reflux system. Once the aliquot was free of $\mathrm{H}_{2} \mathrm{O}_{2}$, COD analysis was performed. with the method 29 (25 to $1500 \mathrm{mg} / \mathrm{L}$ ), the analysis system Spectroquant ${ }^{\circledR}$, UV-VIS spectra were determined using a spectrophotometer Perkin-Elmer model Lambda 20.

Microbiological assays allow estimation of $\mathrm{CFU} / \mathrm{mL}$ of both of the initial and final irradiated samples is also useful for assessing the ability of $\mathrm{UV} / \mathrm{H}_{2} \mathrm{O}_{2} / \mathrm{O}_{3}$ system.

The nutritive agar is a media in which a lot of microorganism, whom are not extremely exigent in their nutritional needs, could be developed. The MacConkey agar is a selective and differential medium used to selectively isolate and identify Enterobacteriaceae with Salmonella, Shigella and coliform from feces, urine, sewage and a variety of foods

\section{Decimal dissolutions method and planting by plate stria.}

The preparation of decimal dilutions of a sample is intended to perform progressive solutions of the sample for achieving accurate microbial counts, incubation at $37^{\circ} \mathrm{C}$ for 24 hours

\section{RESULTS AND DISCUSSION}

To validate the results, the parameters of the initial sample were determined for comparative reference. Aliquots were taken every $5 \mathrm{~min}$. Table 1 contains the experimental data collected during the use the batch photo-reactor, COD decreased from 195-166 mg/L and $\mathrm{Ca}^{2+}$ ion was $388 \mathrm{mg} / \mathrm{L}$.

Turbidity and color parameters have a tendency decrease into the first 5 minutes, after that, the results shows an increment of the variable, this is due to the precipitation of the temporary hardness of water caused by the warming process induced by the lamps operation. To confirm that argument, the last aliquot was filtered; color value and turbidity reduced of $0.7 \mathrm{~m}^{-1}$ and $1 \mathrm{FNU}$ respectively, the turbidity below the sensitivity of the method employed. Figure 1, exhibit the UV-vis spectra after each interval of exposure to irradiation of the sample, the concentration of contaminants that absorb in this region is lower (lower area under curve) in this case, the last aliquot shows a UV-vis spectrum that manifest a greater area than the penultimate, due to heating and subsequent precipitation of the temporary hardness of the sample, this exhibits a slight turbidity.

The amount of residual hydrogen peroxide was removed through a reflux system, this procedure avoids interference with the method used for the final COD evaluation.

In the case of the photodegradation with the solar collector, aliquots were extracted after 
each hour of irradiation. Table 2 shows the parameters obtained in the solar collector after each hour. The COD was reduced from 195 to $132 \mathrm{mg} / \mathrm{L}$. The photochemical treatment carried out in the solar collector turned out to be effective because there was a decrease in the parameters of color, turbidity and COD.

Nevertheless, $\mathrm{pH}$ values were increased slightly in the different time intervals, due wing formation of bicarbonates and carbonates.

Figure 2 shows the UV-vis spectra determined after the wastewater irradiation inside the solar collector. It could be interpreted that the degradation was successful due to the decrease in absorption observed with time of irradiation applied.

\section{Decimal dissolution assay}

In the sample obtained from the advanced primary treatment, turbidity due to microbial activity was observed. Decimal dilutions were performed for each of the samples from the batch photoreactor and the solar collector without any turbidity. However the absence of turbidity does not guarantee the existence of bacterial development,

Table 1: Parameters obtained with the operation of the batch photo-reactor in the $\left(\mathrm{UV} / \mathrm{H}_{2} \mathrm{O}_{2} / \mathrm{O}_{3}\right)$ system

\begin{tabular}{lccccc}
\hline $\begin{array}{l}\text { Irradiation time (min) } \\
\text { Parameters }\end{array}$ & $\mathbf{0}$ & $\mathbf{5}$ & $\mathbf{1 0}$ & $\mathbf{1 5}$ & $\mathbf{2 0}$ \\
\hline $\mathrm{pH}$ & 7.98 & 8 & 8.1 & 8.3 & 8.4 \\
Color $\left(\mathrm{m}^{-1}\right)$ & 11.5 & 4.4 & 6.5 & 7.3 & 7.7 \\
Turbidity (FNU) & 63 & 24 & 24 & 31 & 45 \\
\hline
\end{tabular}

Table 2: Quantified parameters into the water exposed to the solar collector system $\left(\mathrm{UV} / \mathrm{H}_{2} \mathrm{O}_{2} / \mathrm{O}_{3}\right)$

\begin{tabular}{lcccccc}
\hline $\begin{array}{l}\text { Time (h) } \\
\text { Parameter }\end{array}$ & $\mathbf{0}$ & $\mathbf{1}$ & $\mathbf{2}$ & $\mathbf{3}$ & $\mathbf{4}$ & $\mathbf{5}$ \\
\hline $\mathrm{pH}$ & 7.89 & 8.17 & 8.22 & 8.30 & 8.32 & 8.35 \\
Color $\left(\mathrm{m}^{-1}\right)$ & 11.5 & 6.5 & 7.3 & 7.7 & 4.3 & 1.7 \\
Turbidity (FNU) & 63 & 31 & 37 & 45 & 23 & 9 \\
\hline
\end{tabular}

Table 3: Characteristic of the colonies identified into the residual wáter

\begin{tabular}{llll}
\hline Size & Color & Texture & Microorganism \\
\hline big & Rose & Mucoid & Kleibsiella \\
big & Rose & No mucoid & Enterobacter, Escherichia coli \\
\hline
\end{tabular}

Table 4: Observed Characteristics on CHROMagar Orientation

\begin{tabular}{lll}
\hline Color & Colony $\mathbf{1}$ & Colony 2 \\
\hline Metalic blue & Kleibsella, Enterobacter, Citrobacter & \\
Turquoise blue & & Enterococos \\
\hline
\end{tabular}




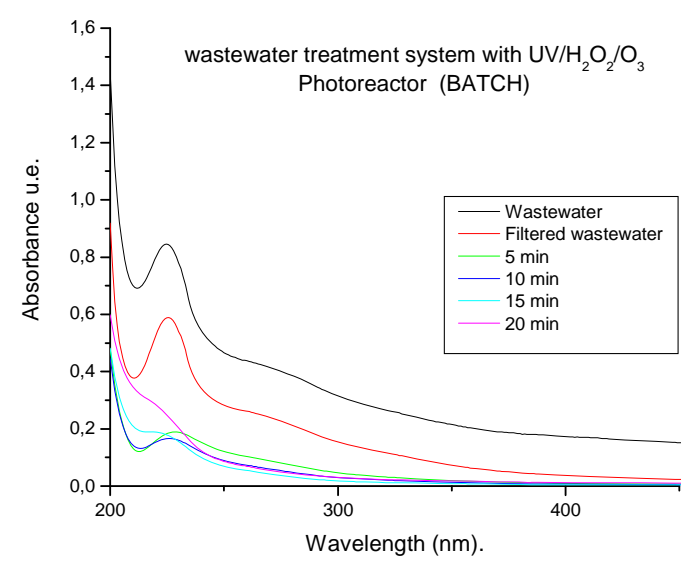

Fig. 1: UV-vis spectra obtained from the photodegradation in the batch system each 5 minutes

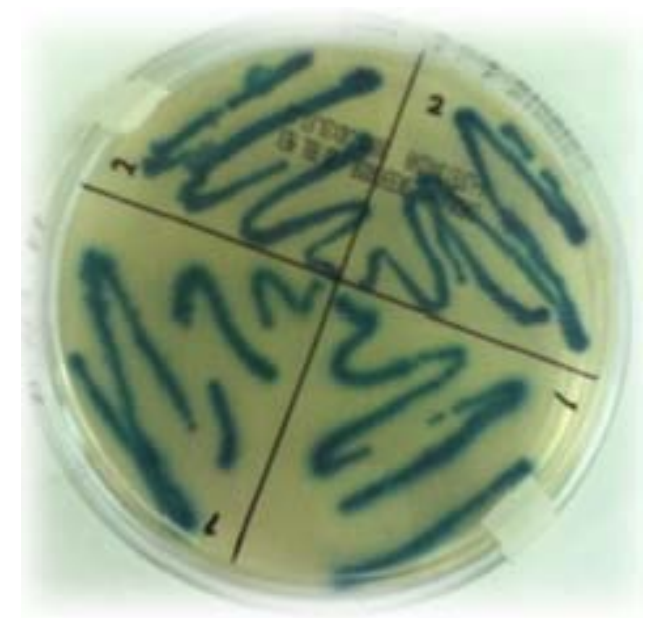

Fig. 3: Plating of CHROMagar Orientation

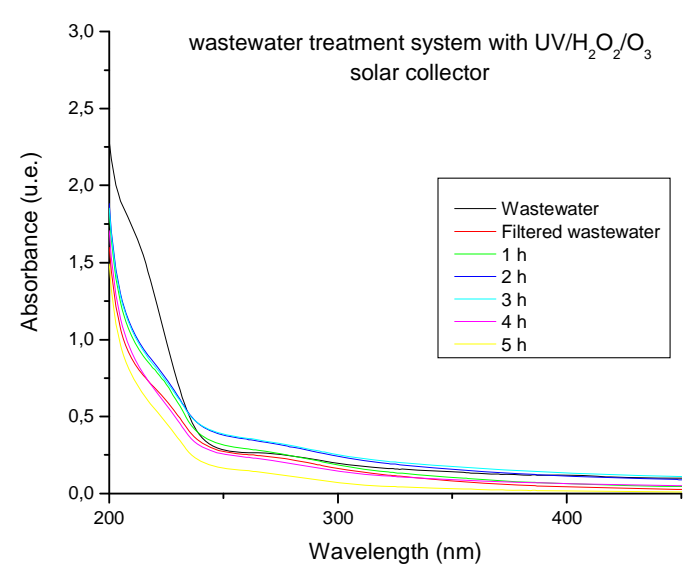

Fig. 2: Spectra obtained from the aliquots from the photodegradation developed into the solar collector at intervals of 1 hour

for that reason, a testing of planting by plate stria ascertainment is required. Method of Planting by plate stria of the composed effluent sample. As a result of the planting by plate stria it was observed a colloidal growing, making possible the isolation and identification of the microorganism via properties of the used agar. The sample is subjected to the same test, the planting of $5 \mu \mathrm{L}$ of residual water. It can be quantified a $41 \mathrm{CFU}$ total into the plate number 6 , equivalent to $8.2 \times 10^{8} \mathrm{CFU} / \mathrm{mL}$ of residual water.

After the colonies accounting, they were classified and isolated, the BIOXON manual for their size, color and texture was consulted (table 3).

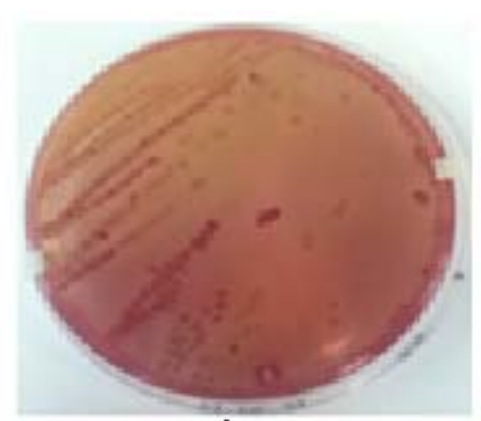

a)

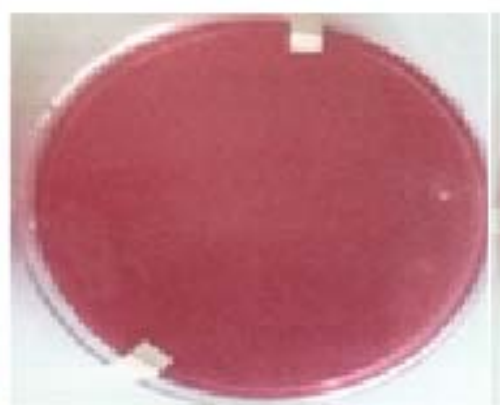

b)

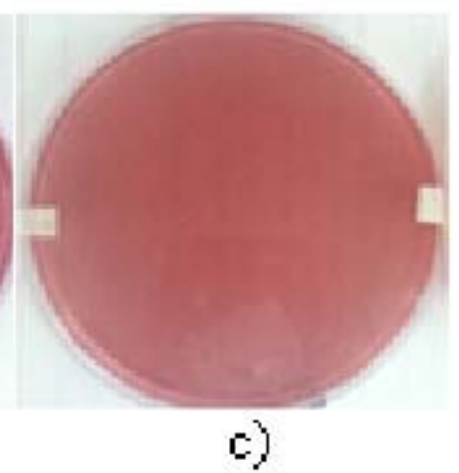

c)

Fig. 5: Comparison of the planting of the dilution 10 of the residual (a), planting of the dilution 1 of the water treated 5 minutes into the batch photoreactor (b) and the planting of the dilution 1 after 1 hour of residual water treated by the solar collector (c) 
With the finality of validity the identification a chromogenic CHROMagar Orientation media has been used. The colonies indicators obtained were: metallic blue into quadrant number 1 and turquoise blue in quadrant number 2 (figure 3 ). Their characterization requires their media color comparison (table 4).

Assay via planting plate stria of the aliquots coming from photochemical treatment.

The irradiated solutions at different times into both the batch photoreactor and solar collector were planted by plate stria method and were incubated at $37^{\circ} \mathrm{C}$ during 24 hours without bacterial growing; therefore the disinfectant treatment applied was validated, obtained the $100 \%$ of efficiency.

The figure 5 presents a comparison of plate resulted of the planting at dilution 10 of the sample (a), which contains an uncountable number of CFU; the plate (b) obtained from the planting of dilution 1 , form the aliquot extracted after 5 minutes of treatment into the batch photoreactor, denotes a null growing of CFU; that plate (c) resulting from the planting of dilution 1 collected after 1 hour of treatment with the solar collector, shows a null growing of CFU too.

\section{CONCLUSION}

With the treatments applied it is possible to improve the $\mathrm{pH}$, color, turbidity and COD parameters for the residual water obtained from the primary advanced process. Furthermore, with the obtained results into the UV-vis spectrum a chemical transformation of the organic contaminants, which are present into the residual water and absorb in that region of the electromagnetic spectrum, was observed. Therefore, the advanced oxidation treatment application using a $\left(\mathrm{UV} / \mathrm{H}_{2} \mathrm{O}_{2} / \mathrm{O}_{3}\right)$ system represents an available alternative for the conditioning of residual water from a previous process of primary advanced treatment.

With the comparison of the results of the photodegradation developed both into a batch reactor and a solar collector, it is demonstrated that both treatment systems are efficient. However, the use of the solar collector represents a better alternative for to accomplish the organic contaminants transformation at low cost; this is due to the employment of the solar radiation as a source of UV, in contrast with the batch reactor who consume $1000 \mathrm{~W} / \mathrm{h}$ of electric energy.

Microbiological assays demonstrated the disinfection capacity of the photodegradation treatment with the (UV/H2O2/O3) system, into the batch photoreactor as in a solar collector, from the first aliquot collected.

\section{ACKNOWLEDGEMENTS}

The authors are thankful for the financial support given by VIEP-BUAP

\section{REFERENCES}

1. Charaborty, C,; Hug, M,; Ahmed, S,; Tabassum, T,; Miah, R. Analysis of the causes and impacts of water pollution of Buriganga river, Int J Sci Technol Res 2013;2(9):245252.

2. Zhao, W,; Ting, Y.P.; Chen, J.P.; Xing, C.H.; Shi, S.Q. Advanced primary treatment of waste water using a bio-flocculation-adsorption sedimentation process, Act Biotechnol. 2000;20(1):53-64.

3. Sharma, S,; Ruparelia, J.P.; Patel, M.L. A general review on Advanced Oxidation Processes for waste water treatment
International Conference on Current Trends in Technology NUiCONE 2011:1-7.

4. Hernández, F.; Geissler, G. Photooxidative treatment of sulfurous water for its potabilization, Photochem. Photobiol 2005;81(3):636-640.

5. Rendón, T.; Hernández, F.; Castillo, J. Solar photochemical Pre-treatment for sulphurous ground water Purification Process, J. Chem. Chem. Eng., 2011;5(9):793-798.

6. Sirtori, C.; Zapata, A.; Oller, I.; Gernjak, W; Agüera, A.; Malato, S. Decontamination industrial pharmaceutical wastewater by 
combinig solar photo-Fenton and Biological Treatment, Water Res., 2009;43(3):661-668.

7. Chelme-Ayala, P.; Garnal, M.; Smith, D. Degradation of bromoxynil trifluralin in natural water by direct photolysis and UV plus $\mathrm{H}_{2} \mathrm{O}_{2}$ advanced oxidation processes, Water Res., 2010;44(7):2221-2228.

8. Andreozzi, R.; Caprio, V.; Marotta, R.; Radovnikovic, A. Ozonation and $\mathrm{H}_{2} \mathrm{O}_{2} / \mathrm{UV}$ treatment of clofibric acid in water: a kinetic investigation, J. Hazard. Mater., 2003;103(3):233-246.

9. Arslan-Alaton, I.; Tureli, G.; Olmez-Hanci, T. Treatment of azo dye production wastewater using Photo-Fenton-like advanced oxidation processes: Optimization by response surface methodology. J. Photochem. Photobiol. A: Chemistry. 2009;202(2:142-153.

10. Zhang, J.; Joshio, N. Mechanism of the $\mathrm{OH}$ Radical Generation in Photocatalysis with $\mathrm{TiO}_{2}$ of Different crystalline Types, $\mathrm{J}$. Phys.Chem. C. 2014;118:10824-10832.

11. Kumar, B.; Khairallah, R.; Bibi, K.; Mazza, A.; Gehr, R.; Masson, L.; Frigon, D. Impact of UV and PAA disinfection on the prevalence of virulence and antimicrobial resistance genes in uropathogenic Escherichia coli in wastewater effluents. App. Environ. Microbiol. 2014;80(12):3656-3666.

12. Byappanahalli, M.N.; Nevers, M.B.; Korajkic, A.; Staley, Z.R.; Harwood, V.J. Enterococci in the environment. Microbiol. Mol. Biol. Rev. 2012;76(4):685-706.

13. Frigon, D.; Biswal, K.; Mazza, A.; Masson, L.; Gehr, R. Biological and Physicochemical Wastewater Treatment Processes Reduce the Prevalence of Virulent Escherichia coli. Appl. Environ. Microbiol. 2013;79(3):835844.

14. Wang, X.; Hu, Y.; Xia, Y.; Wen, X.; Ding, K. Pyrosequencing analysis of bacterial diversity in 14 wastewater treatment systems in China. Appl. Environ. Microbiol. 2012;78(19):7042-7047.

15. Agostini, F.; Sundberg, C.; Navia, R. Is biodegradable waste a porous environment? A review. Waste Manag. Res..2012;30(10):1001-1005. 